stimulations, in which he used Marey's tambours, to the faces of which were attached the instruments of contact.

HARVARD UNIVERSITY.

Robert MacDougall.

\title{
REMARKS ON TIME PERCEPTION.
}

The opening article in Mind for January, 1900, reviewing the contradictory results of Schumann and Meinong in experimenting on time perception in relation to memory-image, is of interest, but fails to note the fundamental difficulties of the subject. In the first place, we must remark on the confusion of objective and subjective time, as when Schumann (p. 3) takes a 'note heard for one second,' a 'tone sensation of one second's duration,' as a standard of subjective value. But to work on a purely subjective problem from objective artificial time is plainly confusing. If we are to understand the content of time perception we must study introspectively and genetically. What are the origin and development of time perception under natural selection?

An organism, pressed by hunger, senses food, and the interval of steps toward the realization is felt as timeful. If realization is absolutely immediate, there is no time sense, as seems often to be the case with infants; but even with them delayed realization of satisfaction brings time perception. From the moment that appearance is seen to be only the sign of reality, that is from the origin of knowledge, we thus find time perception accompanying the progressive steps of realization. Time perception is then bound up with delay and the use of means, and is implied in skill, patience and perseverance, the cardinal intellectual virtues by which organisms save themselves and make progress in the struggle of existence. The genesis then of the time perception under natural selection is in a felt relation of the individual to its environment, and it is a complex of sense of unrealization and of position with reference to realization. And it is also plain, e.g., with infants, that time perception is not experience of mere succession, but of delayed succession which comes with sense of unreality. And time perception is seen to be an adaptive psychosis to exigencies, giving foresight and preparedness, and reducing fright to caution.

The rise and growth of time perception are then involved in expectant attention which implies memory and the cognition of the break between the real and the ideal-that real and ideal are not coincident factors. We may consider that with very young animals and children time perception is solely confined to a purely subjective feeling when food is brought to them. How time perception is related to expectant 
attention is easily observed in common experiences. In the train the other day I was not aware of any particular time perception when stopping at a station, but when I watched the objects fly by as the train increased speed, I noticed that time perception became very acute with the increased rapidity of expectant attention, and vice versa as the train slowed down.

In this case and others it is plain that the amount of time perception in a given amount of objective time-say one minute-is determined by the rate of consciousness itself. A very simple experiment shows this. While in your usual frame of mind, with consciousness at its usual pace, thinking over a common matter-e. g., planning some ordinary experience, as a trip to the country-estimate the watch time; then, while in the same mood, estimate while taking exercise, as running up and down stairs. With one person, in whose introspective honesty I had confidence, and who did not count and was entirely. unsuspicious of the object in view, the acceleration was remarkable. It required 150 seconds actual time for the 90 -second time estimate when at rest, while during and after exercise the 90-second estimate was given after only 55 seconds actual time. He ascribed the variation, when he felt 55 seconds to be as long as 150 previous, to increased rapidity of consciousness. And under primitive conditions, when no objective time is known, as with most animals which probably do not appreciate even the natural day as objective time-length, this subjective time increases with expectant attention and rapidity of consciousness. So when a man is drowning his consciousness is forced to top speed, like a lightning-shutter, and time perception is most acute. (The effect on consciousness itself of reiteration in consciousness under expectant attention is time-perception as feeling of experience-room.) When on the train the speed reaches the limit of my perceptive power as to distinct objects, the time perception is keenest, and if it goes beyond, and the landscape becomes mere blur, time perception is lessened and even lost.

Pure subjective time is then a mode of introspection and self-consciousness, and probably the earliest form. Experience here is reflex, first turns upon itself, is aware of itself in deferred realization. The dragging interval is measured by how many consciousnesses active and potential go into it, as unrealizations. Thus to the very thirsty invalid the interval while the nurse is bringing drink is felt in terms of the number of unrealizations in the eager pulse of the waiting consciousness. So the stolid invalid would have little time perception. Notwithstanding that the rate of consciousness determines amount of time 
perception, yet it is plain to simple introspection that any given act of consciousness is per se timeless, is merely the time unit or point, just as spaceless points compose space. Then there is no 'duration-block' as ' unit' of our perception of time (James), nor can we admit Schumann's simple feeling of duration. Just now $\mathrm{I}$ hear a bell tolling, and $I$ listen to the note as a continued vibration, the whole being felt as a specious present; but a little analysis shows that the time-fullness is felt only as experience-room for quite a number of simple immediate consciousnesses, that is, of passing units. If I perceive a musical note as a whole of time-a duration-it is as a continuance through a number of consciousness beats which are each subjectively timeless. The phrase 'as quick as thought' could have no meaning except through objective time. Every duration is such only as a whole of felt successions actual or potential. This does not deny, of course, that the ear-grasp of time wholes is real, and with natural and trained musicians doubtless the feeling is apparentiy of simple duration, the process of potential units being subconscious. And so when James says ('Psychology,'I., p. 630): "And since we saw a while ago that our maximum distinct intuition of duration hardly covers more than a dozen seconds (while our maximum vague intuition is probably not more than that of a minute or so), we must suppose that this amount of duration is pictured fairly steadily in each passing instant of consciousness by virtue of some fairly constant feature in the brain-process to which the consciousness is tied," we see here the confusion of subjective and objective time, as if each psychic pulse were apperceptive of itself as taking seconds of time, whereas time consciousness has a very considerable development in purely subjective form before it ever apprehends objective time in any form, and especially in seconds or fractions. And I cannot find in my introspection that the psychic moment ever directly apperceives itself, but I see each psychic beat as a timeless instantaneous act, yet the sum of the acts constituting subjective time. Hence the feeling of immense duration with drowning people when an immense actual and potential experience-room is felt, in fact a life-room.

As to the specious present or 'now' we must, as implied from our previous discussion, dissent from James' dictum: "But the original paragon and prototype of all conceived times is the specious present, the short duration of which we are immediately and incessantly sensible." The shortly to be, and the shortly has been, interpreting the former, are much more primitive. The sense of 'now' has no direct simple value for struggle of existence, and is reflective. Any unity of experience is interpreted as a 'now,' as in hearing a long-drawn 
whistle or musical note of even quality; and if the whole of life experience were an absolute unit and uniform, and so no break of reality and ideality, we could have an eternal 'now.' The specious present, of course, appears as a sum of possible psychic beats; it is not the elementary timeless component of time, but is given as duration, as a block of experience.

It is important, as we have said, to keep in mind the distinction of subjective and objective time, to note that the psychics of time and the psychophysics are distinct areas of investigation. The rise and development of objective time as well as that of subjective time can only be determined by very delicate and thorough observation and experimentation on infants and animals, reinforced by study of adults, extremely little having been accomplished along these lines as yet. And what stage in mind and why under natural selection do changes in environment, such as day and night, suggest definite intervals of time? That many domestic animals have the feelings of time by some objective notation has seemed probable to some, yet it may be that they fix upon some sign and association merely, and do not mark real intervals. The horse which quits work at the noon whistle does not regard the whistle as a time limit, but merely as a sign of food and rest. Of course in the primitive form objective time may arise merely as keeping tab on the subjective time of expectant attention, and the regulation of subjective time to normal objective time relations is plainly of high utility. Thus the infant suffers much from strained attention, because you cannot make it understand that five minutes are required to heat its food. So animals may come objectively to regulate subjective time. Again, you look at your watch five minutes before the curtain rises at the theatre, and you have in the succeeding waiting a constant flow of both subjective and objective time. The beat of consciousness tends to assimilate to objective beats, as the ticking of a clock may seem either faster or slower than the present consciousness, too slow, say when I am waiting for a train, too fast when in quiet reflection; yet the tendency will be to synchronize subjective and objective time. You feel at the theatre a great length of time, and you keep correcting this by seconds and minutes subjectively estimated, so that you know with practical certainty when the five minutes are up, though you have in that time had more time perception than perhaps in the whole of the previous week. From the psychological point of view, of course, the subjective time is the real time.

The basis of time-perception we have seen to be psychological reflex in the discordance of the actual and real. So physiological time 
as from pulse, respiration, etc., is a mode of objective time, and quite late in development; for young animals and children who are keenly alive to time in expectant attention are far from being physiologically observant. Normal life in early stages gains little from physiological reflex, but a consumptive would be likely to note respiration time. Nor is physiological time the basis of our estimation of artificial time in hours and minutes, as we see plainly in the Magee case (Amer. Journ. Psychology, VII., 450). He, while out with a camping party, keeps mentally the objective time almost to the minute, and can report whether waked from sleep or climbing a hill the hour and minute correctly, in all of which pulse, respiration and leg time are highly variant. It is obvious in this case, at least, that, as timer of athletic events, his consciousness has formed the habit of objective time-keeping in second beats, minute beats, etc., in a purely direct way without physiological basis, and thus the counting time goes on subconsciously. And here then is an example of subconscious time estimation to which we call the attention of the Editor of Mind, who dissents as to evidence.

And it is plain that if all time-pieces were suddenly destroyed, such men as Mr. Magee would become human time-pieces, and would find their function and existence in this time-knowledge, and for scientific purposes, e. $g$., astronomical and physical, there would tend to arise time-keeping species of men; and as the demand ever became keener for accurate and delicate time-keeping there would be response in the evolution of human society. That is the limit of the minimum consciousness beat as time-measurer can not be defined a priori physiologically, but is controlled by demand in the competition of existence.

What then is the significance of indifference point? Does not this suggest to physiology, as to pulse? There may very well be a coordination of artificial and physiological time, but this does not prove primitive state or genesis. But the objective time which is most constantly estimated correctly might be, say with Mr. Magee, quite different from the 75 seconds in difference point. Mr. W. S. Johnson's 'Researches in Practice and Habit' (p. 52) conclude against indifference point. There must be a much wider range of experiment with all kinds of men and animals in all kinds of physical and mental states to get real light on this question of indifference point.

LAKR FORIST, ILL.

Hiram M. Stanley. 